\title{
Model-based monitoring of temperatures and heat flows in the milling cutter
}

\author{
T. Augspurger $^{1}$ - G. Da Silva ${ }^{1}$ - D. Schraknepper ${ }^{1} \cdot$ P. Mattfeld $^{1} \cdot$ T. Bergs $^{1}$
}

Received: 15 January 2020 / Accepted: 23 March 2020 /Published online: 25 April 2020

(C) The Author(s) 2020

\begin{abstract}
The quantification of the heat flow distribution in the cutting zone is still an unsolved problem from an analytical as well as experimental perspective. Yet the heat flows into the tool and the time-variant temperature fields in the tool significantly influence the tool wear rate. This publication shows the results of a model extended measuring approach in order to monitor as well as investigate heat flows and their partitioning in the milling process under dry conditions. Therefore, the cutting power in the process was measured by means of a dynamometer as well as the temperature in the tool by an embedded thermocouple. The time response of the embedded thermocouple was accounted by an analytical time response function. By further data post processing of the temperature, the heat flow into the tool was inversely determined by comparison of the measured temperature trend at a distinct point with an analytically modeled, transient temperature as a solution of the heat conduction equations by a Green's function. As input into the analytical model, an iteratively determined partition of the measured time-variant cutting power signal was used. The results showed a decreasing heat partition into the tool with rising cutting velocity. The introduced approach is a valuable tool not only to determine the heat partition in the milling process but also to understand and monitor the comprehensive thermo-mechanical conditions in the cutting zone. Understanding and monitoring thermo-mechanical conditions in the cutting process finally enable the exploitation of economic and ecologic process potentials.
\end{abstract}

Keywords Milling $\cdot$ Temperature measurement $\cdot$ Analytical temperature modeling $\cdot$ Heat partition $\cdot$ Tool wear

\section{Introduction-measurement and modeling of temperatures in milling}

Milling is a manufacturing process with a circular cutting movement of a usually multi-tooth tool, rotating around a fixed axis with a direction of cut perpendicular or sometimes transverse to the tool's axis of rotation. Due to its interruption and kinematics, as the superposition of a rotatory and a transverse movement, the milling process produces discontinuous chips with varying chip thickness as shown in Fig. 1. Depending on the tool's rotation and feed direction, the process can be distinguished into up and down milling or a combination of those with further implications regarding chip formation and affiliated non-steady-state cyclic conditions of the

T. Augspurger

T.Augspurger@wzl.rwth-aachen.de

1 Laboratory for Machine Tools and Production Engineering (WZL) of RWTH Aachen University, Research Area Manufacturing Technology, Campus Boulevard 30, 52074 Aachen, Germany forces, heat sources, and thus temperatures. Subsequently, the fluctuating heat sources and generated temperature fields lead to cyclic thermal loads of the tool and workpiece with effects on tool wear, surface integrity, and machinability in general [1].

The majority of the mechanical energy $P_{\text {total }}$ in the milling process is transformed into sensible heat in form of a heat flow into the tool $\dot{Q}_{\text {tool }}$, the workpiece $\dot{Q}_{\text {workpiece }}$ into the chip $\dot{Q}_{\text {chip }}$, and a remain loss as, for instance, heat radiation or the kinetic energy of the chips.

$P_{\text {total }}=\dot{Q}_{\text {tool }}+\dot{Q}_{\text {workpiece }}+\dot{Q}_{\text {chip }}+\dot{Q}_{\text {loss }}$

Following the kinematics representation in Fig. 1 and according to [1], the active force on the cutting edge $F_{\mathrm{a}}$ is split in the normal cutting force $F_{\mathrm{cn}}$ and in the cutting force $F_{\mathrm{c}}$. Those can be obtained from the cutting force components $F_{\mathrm{x}, \mathrm{y}}$ regarding the engagement angle $\Phi$ by

$$
\left[\begin{array}{c}
F_{\mathrm{c}} \\
F_{\mathrm{cn}}
\end{array}\right]=\left[\begin{array}{ccc}
\sin (\Phi) & -\cos (\Phi) & 0 \\
\cos (\Phi) & \sin (\Phi) & 0
\end{array}\right] \cdot\left[\begin{array}{c}
F_{\mathrm{x}} \\
F_{\mathrm{y}}
\end{array}\right]
$$




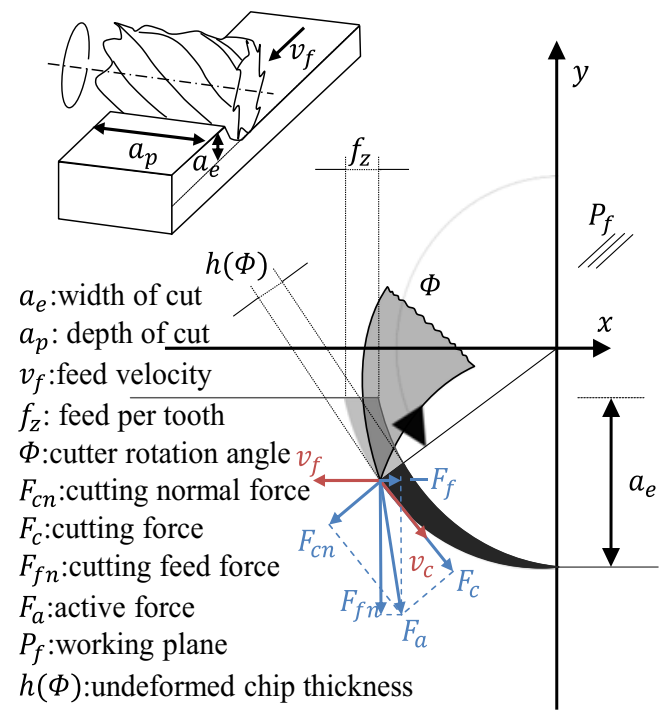

Fig. 1 Down milling kinematics

The total mechanical power in the process is then approximated to

$P_{\text {total }} \approx F_{\mathrm{c}} \cdot v_{\mathrm{c}}$

A process parameter-dependent partition $B_{\text {tool }}$ of the total process power $P_{\text {total }}$ in the cutting zone flows into the tool $\dot{Q}_{\text {tool }}$ causing cycling temperature fields with a maximum amplitude at the tool tip. Those high frequent temperature fluctuations cause alternating strains in the material and finally cracks as well as tool wear $[2,3]$. At the same time, a defined partition of heat flows into the workpiece $\dot{Q}_{\text {workpiece }}$, where it heats the surface layers which are also prone to mechanical stress due to the acting cutting force components. The combined thermo-mechanical load may alter the surface's microstructure, which defines the parts functionality in the later application $[4,5]$. The majority of the dissipated heat in the cutting zone is carried away with the chip $\dot{Q}_{\text {chip }}$, which causes a temperature maximum at the tool-chip contact zone due to rubbing and deformation effects.

Thus, the understanding of the heat partitioning and the affiliated temperature fields in the cutting zone is a key factor for the efficient process design with regard to tool wear and surface integrity and their economical and ecological impact. In this publication a real-time measurement system was used in order to directly measure temperatures and forces in the milling process. By thermodynamic considerations at the usage of an analytical temperature model, finally the inverse quantification of the heat partition into the tool was aimed for.

A state-of-the-art approach in order to measure temperatures in the milling cutter is the embedded thermocouple and the usage of a storage device or a wireless system, which transmits data from the rotating tool holder to a stator. However, this approach is afflicted with two major problems:
First, the not arbitrarily small proximity of the measurement point of the thermocouple to the tool's rake face, where the temperatures cycle at their maximum. With regard to the spatial distribution, temperature gradients of several hundred degrees in the submillimeter range may occur at the same time. Second, thermocouples bring the advantage of a precise and reliable measurement of punctual temperatures, but they typically do not reach reaction times below $100 \mathrm{~ms}$, which are only possible for types below $0.5 \mathrm{~mm}$ in diameter welded to the bottom of the blind hole. However, also solutions based on thermocouple coatings may approximate those domains $[6,7]$.

Thus a typical approach for the measurement of nonsteady-state temperatures with thermocouples is by the usage of a transient temperature model such as the solution for the temperature field in the tool approximated by a semi-infinite corner by means of Green's functions.

Stephenson and Ali [8] picked up the approach in order to model the punctual transient temperatures in the tool during interrupted cutting by approximating the tool geometry with a semi-infinite rectangular corner. In their investigations, they examined the influence of uniform, linear, and exponential heat source distributions along the rake face as well as timevarying heat source intensities in the form of square wave heat inputs.

According to Stephenson and Ali, the Green's function for the temperatures in a semi-infinite corner due to an instantaneous point source at time $\tau$ at the surface point $x=x_{\mathrm{p}}, y=y_{\mathrm{p}}, z=0$, assuming adiabatic conditions at the boundaries, can be obtained by multiplying the Green's function for three mutually perpendicular instantaneous plane sources in semi-infinite half spaces. Those intersect to form an eighth space or corner as shown in Fig. 2. Thus, the transient temperature field $T(x, y, z, t)$ at a point $x, y, z$ in the corner at the time $t$ can be described as a solution of the governing differential equation for transient heat conduction within a continuous medium to

$$
\begin{aligned}
& \frac{\partial^{2} T}{\partial x^{2}}+\frac{\partial^{2} T}{\partial y^{2}}+\frac{\partial^{2} T}{\partial z^{2}}=\frac{1}{a} \cdot \frac{\partial T}{\partial t} \\
& -\lambda \cdot \frac{\partial T}{\partial z}=\dot{q}^{\prime \prime}(x, y, t) ; 0 \leq x \leq L_{x} ; 0 \leq y \leq L_{y} ; z=0 \\
& T(x, y, z, t)=\frac{a}{\lambda} \int_{0}^{t} \int_{0}^{L_{x}} \int_{0}^{L_{y}} \Theta_{G}\left(x, y, z, t, x_{\mathrm{p}}, y_{\mathrm{p}}, 0, D\right) \\
& \cdot \dot{q}^{\prime \prime}\left(x_{\mathrm{p}}, y_{\mathrm{p}}, \tau\right) d y_{\mathrm{p}} d x_{\mathrm{p}} d \tau
\end{aligned}
$$

The variable $a$ represents the thermal diffusivity of the tool material and $\lambda$ its heat conductivity. The term $\dot{q}^{\prime \prime}\left(x_{p}, y_{p}, \tau\right)$ describes the spatial and temporal distribution of the heat flux of the instantaneous, punctual heat sources, and the Green's 


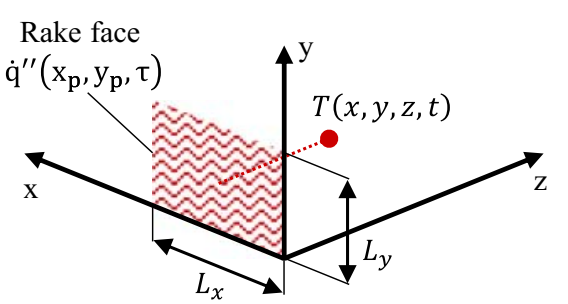

Fig. 2 Semi-infinite rectangular corner

function of the relevant geometry $\Theta_{G}$. The size $L_{\mathrm{x}, \mathrm{y}}$ and temporal distribution $\tau$ of the heat source are of particular significance for the resulting temperature field, especially for the maximum temperature generated. By applying a negative heat flow for $\dot{q}^{\prime \prime}\left(x_{p}, y_{p}, \tau\right)$, a cooling effect may be modeled. According to Fig. 2, for a spatial uniform heat source, the Green's function $\Theta_{G R}$ for an instantaneous heat impulse over the patch $0 \leq x \leq L_{\mathrm{x}}, 0 \leq y \leq L_{\mathrm{y}}$ can be approximated by [8]

$$
\begin{aligned}
& \Theta_{\mathrm{GR}}\left(x, y, z, L_{\mathrm{x}}, L_{\mathrm{y}}, D\right)=\int_{0}^{L_{\mathrm{x}}} \int_{0}^{L_{\mathrm{y}}} \Theta_{\mathrm{G}}\left(x, y, z, x_{\mathrm{p}}, y_{\mathrm{p}}, 0, D\right) \\
& \cdot d y_{\mathrm{p}} d x_{\mathrm{p}} \\
&=\frac{1}{2 \sqrt{\pi} \cdot D} \cdot \exp \left(\frac{-z^{2}}{D^{2}}\right) \cdot \Theta_{\mathrm{GU}}\left(x, L_{\mathrm{x}}, D\right) \\
& \cdot \Theta_{\mathrm{GU}}\left(y, L_{\mathrm{y}}, D\right)
\end{aligned}
$$

$\Theta_{\mathrm{GU}}(u, L, D)=\operatorname{erf}\left(\frac{L+u}{D}\right)+\operatorname{erf}\left(\frac{L-u}{D}\right)$.

$D=2 \cdot \sqrt{a(t-\tau)}$.

Physically, $D$ is the scaling factor or characteristic dimension for the penetration of the temperature field at time $t$ due to an instantaneous heat source at time $\tau$.

The precision of the analytical model highly depends on the quantification of the time-dependent and spatialdistributed amount of heat $\dot{q}^{\prime \prime}\left(x_{p}, y_{p}, \tau\right)$ entering the tool. For such a quantification, Stephenson and Ali used the model of Loewen and Shaw [9] for steady-state cutting temperatures calculating the total friction energy per unit time and per unit area dissipated at the chip-tool interface depending on the friction force, chip velocity $v_{\mathrm{ch}}$, chip contact length $l_{\mathrm{ch}}$, and chip width $b$. Using the relations between thermal properties of the workpiece and tool materials, obtained in [10], the fraction of heat entering the chip and the tool was calculated. An extensive transient model for the heat input into the tool depending on cutting parameters like the cutting velocity $v_{\mathrm{c}}$ for the milling process was not constituted. Yet Stephenson and Ali obtained a validation of the model for overall surface temperature levels and the effect of varying heating time, validated by the tool-chip thermocouple method [10]. The results showed generally lower tool temperatures in interrupted cutting than in continuous cutting. A major influence on the temperatures was identified as the duration of heating cycles and cooling cycles as well as their ratio. Quantitatively, the analysis underestimates temperatures for short heating cycles and underestimated the rate at which temperatures approached a steady state at the beginning of each cycle. The author pointed out that the accuracy of the analysis could be improved by using a transient model to calculate the amount of heat entering the tool from the tool-chip contact.

Sato et al. used the Green's function model in order to predict punctual temperatures in the milling tool, which they validated by a tool integrated ratio pyrometer in a distance from 0.1 to $0.5 \mathrm{~mm}$ to the rake face. For the spatial heat flux distribution over time, a varying tool-chip contact length was approximated by an analytical function of the cutter rotation angle and the undeformed chip thickness. The calculation of the heat flux per unit area at the rake face was calculated by the measured cutting force and assumed as uniformly distributed. The heat partition ratio of the heat flux into the tool $B_{\text {tool }}$ was determined experimentally by comparing the calculated peak temperature to the measured peak temperature at a depth $z=0.1 \mathrm{~mm}$. The ratios were given as $12.2 \%$ and $12.1 \%$ in up and down milling, respectively. However, they did not use a tool-embedded thermocouple in order to measure the temperatures but a tool integrated ratio pyrometer setup by means of two separated fibers and a coupler in the machine tool. [11]

Jiang et al. integrated an analytical model for the contact length in order to perform a time-dependent spatial heat source distribution on the rake face due to the varying undeformed chip thickness in the milling process. It posed the input for the Green's function model, which they validated by thermocouples integrated into the tool. A least square optimization algorithm proposed by Beck et al. [12] determined the heat flux into the tool and workpiece by solving the inverse heat conduction problems. In their work, they showed that the ratio between cutting time and non-cutting time significantly affects the tool temperature rise under the condition that the cutting velocity, the heat flow into the tool during cutting, and the time for one rotation remain the same. The longer the cutting time, the more steady the temperature rise is in the tool [13].

Karaguzel et al. used an embedded thermocouple in 0.3-mm proximity to the rake face of an uncoated carbide insert for a milling process of AISI 1050 steel with a diameter $d=80 \mathrm{~mm}$ cutter. They investigated the influence of the cutting velocities $v_{\mathrm{c}}=50 \mathrm{~m} / \mathrm{min}$ and $70 \mathrm{~m} / \mathrm{min}$ at $f_{\mathrm{z}}=0.15 \mathrm{~mm}, a_{\mathrm{p}}=1 \mathrm{~mm}$, and $a_{\mathrm{e}}=20,40$, and $80 \mathrm{~mm}$. They used a data acquisition system rotating with the tool holder with a $500 \mathrm{kHz}$ sampling rate storing the data in the device during the cutting operation. The measurement device resolved the temperature fluctuation during the engagement, varying between 100 and $200{ }^{\circ} \mathrm{C}$ for $50 \mathrm{~m} / \mathrm{min}$ and increasing by $25{ }^{\circ} \mathrm{C}$ for $75 \mathrm{~m} / \mathrm{min}$. The heat partition into the tool was determined inversely to $9.6 \%$ by 
the application of a time-variant temperature model based on Green's functions [14].

Baohai et al. used a dual approach for the analytical modeling of transient temperatures in the tool for an end milling process. The cutting cycle was divided into temperature increase and decrease phases. For the temperature increase phase, a model based on Green's functions was proposed. The quantification of the heat flux into the tool and tool-chip contact length was obtained through finite element simulations. In the temperature decrease phase, an analytical onedimensional temperature decrease model for the plate heat convection was proposed. A single wire thermocouple was applied to measure the tool temperature in the conducted milling experiments of Inconel 718 [15].

In a former investigation, the author used a similar experimental setup in order to quantify the effective cooling of $\mathrm{CO}_{2}$ the milling process by extending a temperature sensor with an analytical model predicting its time response as well as the analytical Green's functions model for transient temperature fields in the cutting. However, the setup did not include a ratio pyrometer in order to measure the chip backside temperature neither were the measured transient cutting forces used as input for the analytical temperature model [16].

As demonstrated, most of investigations in the state of the art mainly focus on the temperatures itself but do not systematically investigate the heat partition in relation to the mechanical power input into the process. However, such a thermodynamic view on milling as an energy transformation process may provide valuable insights in the governing causal relationships between process variables and ecological as well as economical target values as tool wear and workpiece quality.

\section{Data acquisition, post processing, and experimental setup}

The following chapter describes the experimental setup depicted in Fig. 3 as well as the real-time measurement system including the sensors used to acquire temperatures and forces in the milling process.

For the calculation of the heat flow distribution in the milling process, a real-time sensor system was used. It integrates a Kistler Type 9255C multicomponent dynamometer, in order to derive the cutting force, together with the spindle rotation encoder. Furthermore, a tool-embedded thermocouple and its transmission system as well a ratio pyrometer, in order to measure the chips backside temperature, were included. The sensors were connected to a NI CompactDAQ 9178 system with I/O NI modules: NI 9215 (BNC) for the wireless transmission module, the two-color pyrometer, and the dynamometer platform and NI 9401 for the spindle encoder. The affiliated LabVIEW software was programmed under the concept of a machine state model and Producer/Consumer pattern for acquisition and recording of data. The modules' timing and sample acquisition were synchronized as a master/slave architecture by a reference clock from the CompactDAQ, as well the start trigger signal.

As thermocouple a type $\mathrm{K}$ with a diameter of $0.25 \mathrm{~mm}$ was placed in a blind hole at a distance of approximately $0.2 \mathrm{~mm}$ from the tool rake face. Thermocouple time response tests in hot oil fluid resulted in a time constant (63.2\%) around $\tau \approx$ $0.05 \mathrm{~s}$, while the time required for the sensor in order to reach $95 \%$ of the oil temperature was $3 \tau \approx 0.15 \mathrm{~s}$.

Thus, for a purposeful comparison between the analytical simulation and the measurement, the behavior of the thermocouple was simulated considering a PT1-behavior. The corresponding functional relationship in the time domain is given by the differential equation:

$T \cdot \dot{y}(t)+y(t)=K u(t)$

In this case $K, K>0$, designates the transmission constant or the gain factor and $T, T>0$, the time constant. The variable $u(t)$ is the input and $y(t)$ the output. For the signal post processing, the time discrete form was used with $\Delta t$ as the scanning increment [17]:

$y_{\mathrm{n}}=\frac{1}{\frac{T}{\Delta t}+1}\left[K u_{\mathrm{n}}+\frac{T}{\Delta t} \cdot y_{\mathrm{n}-1}\right]$

For $T$ a value of $150 \mathrm{~ms}$ for the thermocouple reaction time and a gain factor $K=1$ were used.

A digital telemetry system for strain gauges on rotating shafts from TMS was used to measure the temperature by a customized tool holder as shown in Fig. 3, which generates a magnetic field from the winding transmitting part that enables the inductive transmission of the temperature signal from a pickup coil. According to the hardware data sheet, the module has an accuracy of $\pm 0.5 \%$, while the thermocouples type $\mathrm{K}$ have a typical accuracy of about $\pm 2.2^{\circ} \mathrm{C}$.

The measured thermocouple signal at the positions $x=0.8 \mathrm{~mm}, y=0.8 \mathrm{~mm}$, and $z=0.2 \mathrm{~mm}$ was later compared with an analytically modeled temperature based on Green's method described in the state of the art. It provided the dynamically rising temperatures in order to estimate the heat flow to the tool. According to Eq. 5, the tool temperature simulated in the milling tests was obtained by a numerical integration in MATLAB using a heat flux $q^{\prime \prime}\left(x_{\mathrm{p}}, y_{\mathrm{p}}, \tau\right)$ over time as input data. For the spatial distribution of the planar heat source $L_{\mathrm{x}}$, $L_{\mathrm{y}}$, the depth of cut $a_{\mathrm{p}}$ and $0.5 \mathrm{~mm}$ for the tool-chip contact length was assumed. The thermal diffusivity of the carbide tool $a_{\text {tool }}=1.710^{5} \mathrm{~m} / \mathrm{s}^{2}$ and its thermal conductivity $\lambda_{\text {tool }}=61.5 \mathrm{~W} / \mathrm{mK}$ were determined in a prior investigation of an external laboratory. The intensity of the heat flux distribution over time was derived from the measured total power 
Fig. 3 Experimental setup and data acquisition system

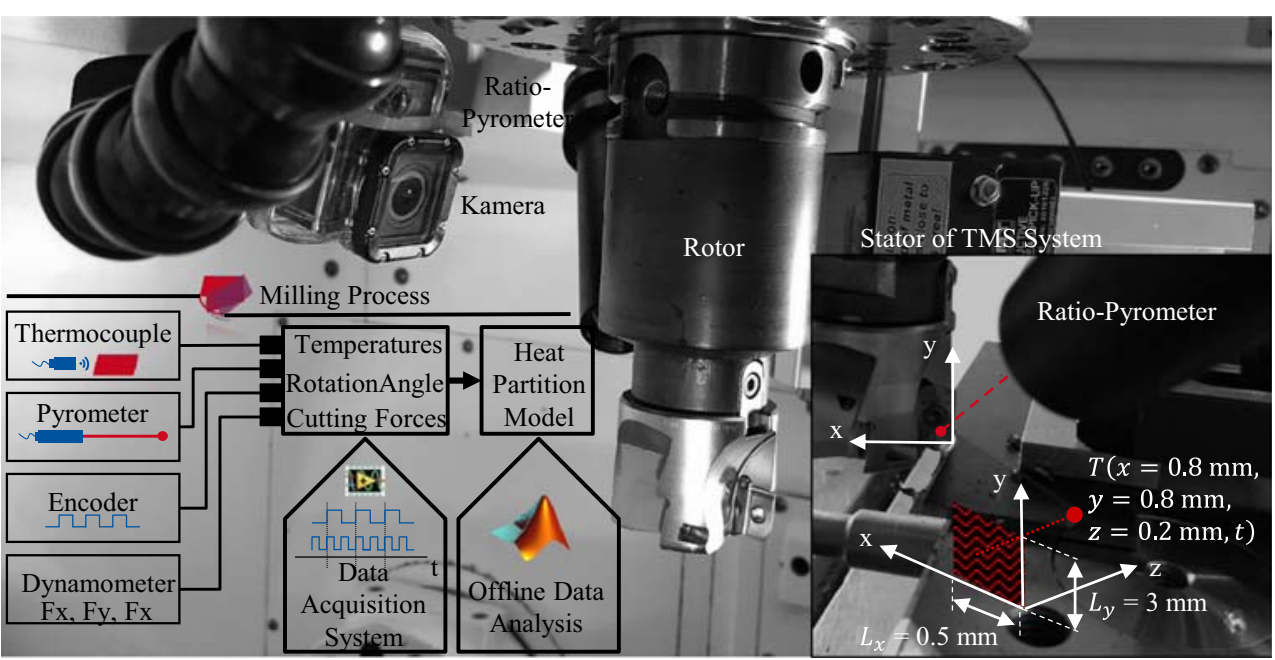

$P_{\text {total }}$ in the process times an iteratively assumed heat partition into the tool $B_{\text {tool }}$.

$\dot{Q}_{\text {tool }}(\tau)=\dot{q}^{\prime \prime}\left(x_{p}, y_{p}, \tau\right) \cdot L_{x} \cdot L_{y}=P_{\text {total }}(\tau) \cdot B_{\text {tool }}$

The three-component forces dynamometer and the spindle encoder were used to calculate the time-variant total power $P_{\text {total }}(\tau)$ generated in the milling tests by Eqs. 2 and 3.

The cutter rotation angle $\Phi$ was obtained by the spindle rotary encoder.

The temperature measurements of the chip's backside were carried out by a ratio pyrometer. The ratio pyrometer is able to derive temperature measurements independent from the surface emissivity at sample rates in the $\mathrm{kHz}$ area. Yet at temperatures below $200{ }^{\circ} \mathrm{C}$, the signal gets noisy and unreliable. Temperatures below $150{ }^{\circ} \mathrm{C}$ are not measurable.

The used ratio pyrometer of type Fire 3 measures the radiation at the wavelengths $\lambda=1.7 \mu \mathrm{m}$ and $\lambda=2.0 \mu \mathrm{m}$ with indium gallium arsenide (InGaAs) detectors. Validity was checked by a black radiation source up to $400{ }^{\circ} \mathrm{C}$.

For the pyrometer a lens was manufactured in order to measure the chip's backside temperature in a distance of $85 \mathrm{~mm}$ within a spot of $1 \mathrm{~mm}$ at the tool's rake face.

An example of the synchronized raw signals is given in Fig. 4. The noisy false measurements of the pyrometer were manually deleted from the graph, in order to provide more clarity. However, for the thermocouple, a longer time scale is given in order to display the tool's continuous temperature rise. Obviously, the thermocouple was not able to capture the cycling temperatures due to its restricted response time but rather a continuous temperature rise reaching a steady state. The bursts are an induced anomaly by electromagnetic fields in the machine.

Figure 4 shows the measured force components $F_{\mathrm{x} \text {, }}$ synchronized to the ratio pyrometer temperature measurement of the chip backside $T$ as well as the spindle rotation encoder over the short time scale of two succeeding tool engagements. The force components $F_{\mathrm{x}, \mathrm{y}}$ together with the cutter rotation angle were then used in Eq. 2 in order to calculate the affiliated cutting force $F_{\mathrm{c}}$.

The milling tests were performed by a CNC milling machine in order to cut $\mathrm{C} 45$ carbon steel plates by a one-cutter tool. The thermocouple was placed inside the cutter hole with copper paste to allow higher heat transfer during the cutting process. The piezoelectric three-component dynamometer platform for heavy application was assembled inside the machine, and the $\mathrm{CNC}$ provided the spindle encoder reading.

During the experiments a $\mathrm{C} 45$ carbon steel plate was cut by five, deviating cutting velocities $v_{\mathrm{c}}=35,70,140,280$, and $560 \mathrm{~m} / \mathrm{min}$ at a radial depth of cut $a_{\mathrm{e}}=9.6 \mathrm{~mm}$, a depth of cut $a_{\mathrm{p}}=3 \mathrm{~mm}$, and a feed per tooth of $f_{\mathrm{z}}=0.05 \mathrm{~mm}$. A seco tool holder with affiliated cutting inserts XOMX180640R-M10 was used. However, only the tool-embedded cutting insert was equipped in the process in order to save material and prevent a cutter run-out error.

\section{Analysis of the results}

The following chapter discusses the results regarding the heat flow and partition to the tool related to the total generated cutting power. For the analytical simulation of the transient temperature fields in the tool approximated by a semi-infinite corner, the introduced analytical model, solving the heat conduction equation by means of Green's function according to Eqs. 5-8, was used. Input was a partition $B_{\text {tool }}$ of the continuous signal of the measured cutting force $F_{\mathrm{c}}$ times the cutting velocity $v_{c}$, thus process power $P_{\text {total }}$ (Fig. 5). Therefore, the measured cutting force signal was approximated via spline fit interpolation in order to generate a function of the heat flow, which was fed into the temperature model. Thus, the temporal heat source trend was accounted close to reality, so is presumably the constant short-time heat partition $B_{\text {tool }}$ into the tool. However, the long-time heat partition into the tool will 
Fig. 4 Raw signals of the measurement system
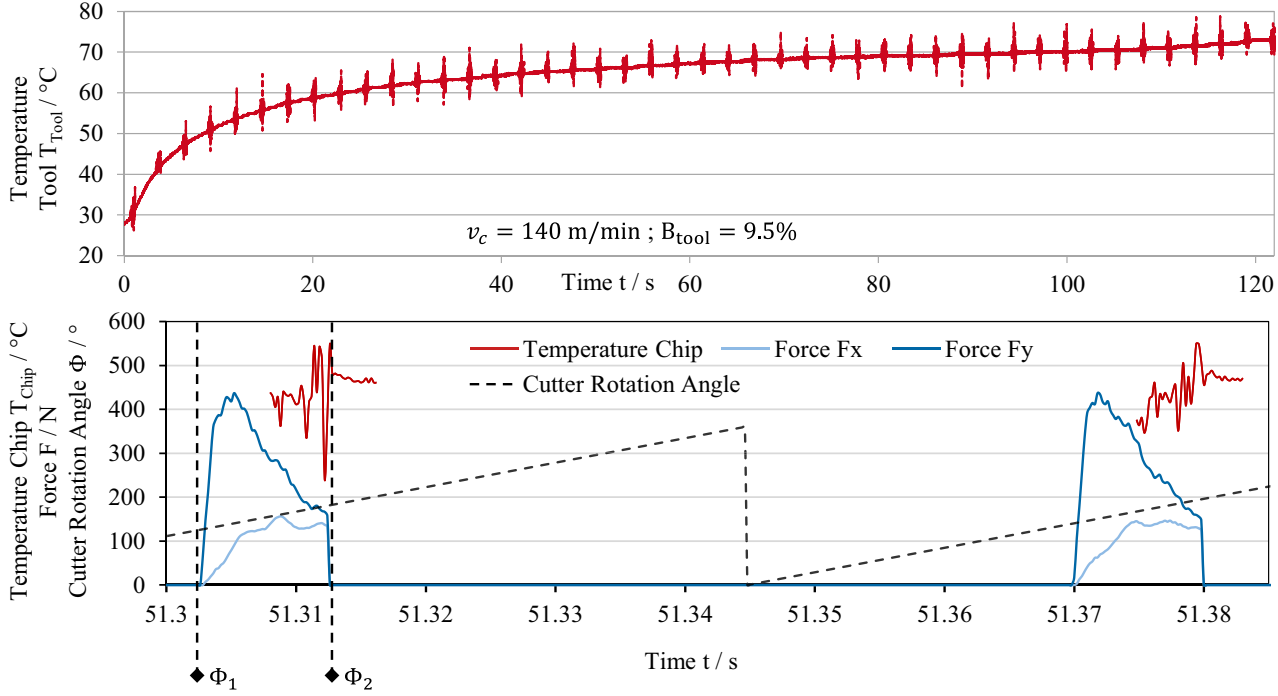

certainly change with tool wear, since the friction conditions in the cutting zone significantly change.

Figure 6 shows the measured and simulated temperature trends in the long and in the short time scale for the investigated cutting velocities. The heat partitions into the tool were iteratively determined by matching the measured and simulated temperatures in the steady state. However, for the cutting velocities $280 \mathrm{~m} / \mathrm{min}$ and $560 \mathrm{~m} / \mathrm{min}$, this steady state was not reached, and the thermocouple measurement showed a further increasing trend. The given heat partition is therefore a minimum estimation, and real values are probably higher.

It can be seen that for the investigated parameter setting and time domain temperatures at the thermocouple measurement point remain below $100{ }^{\circ} \mathrm{C}$. The results further indicate an increasing heat flow into the tool as expected. However, the heat partition into the tool decreases with cutting velocity beginning from $16 \%$ at $v_{\mathrm{c}}=35 \mathrm{~m} / \mathrm{min}$ until $2.7 \%$ at $560 \mathrm{~m} / \mathrm{min}$.

The effect may be explained by the changing relation of heat transport by mass flow to heat transport by conduction in the cutting insert. This relation, also referred to as the dimensionless Péclet number $N_{\mathrm{Pe}}$, was also suggested by Boothroyd for the thermal analysis of the cutting process, making the heat partition fraction $B$ more independent from the regarded case $[18,19]$. According to this theory, the heat generated in the shear zone is increasingly impeded to flow into the tool with an increasing chip mass flow velocity $v_{\mathrm{c}}$. Similar phenomena were also observed in an author's former investigation however related to the heat partitioning between workpiece and chip case [20]. The temperature diffusivity of the workpiece and the tool material in relation to the chip flow velocity therefore have a major influence on the heat portioning in the cutting zone between the chip, workpiece, and tool.

On the right side of Fig. 6, the short time temperature trends of the measurement and the simulation are given. While the measurements show almost no dynamics, probably due to the restricted temporal sensitivity of the thermocouple, the modeled temperatures cycle, however, at low amplitudes due to the relatively high distance to the cutting edge. With an increasing cutting velocity also, those dynamics decline due to the heat source fluctuating at higher frequencies. The irregularities of the model result from the errors in the numerical integration of Eq. 6 over long time scales. It should be pointed out that the model-based approach enables an estimation of not-measureable temperature fluctuations, which are highly relevant for tool wear. It may further enable not only the calculation of the transient temperature at the measurement point of the thermocouple but also at the rake face, where thermal driven wear occurs.

Figure 5 finally shows the effect of an increasing cutting velocity on the decreasing heat partition into the tool in relation to the measured process power. If the heat partition into the tool decreases, the heat partition into the workpiece and/or the chips has to increase.
Fig. 5 Effect of cutting velocity on process power, chip temperature, and heat partition into the tool

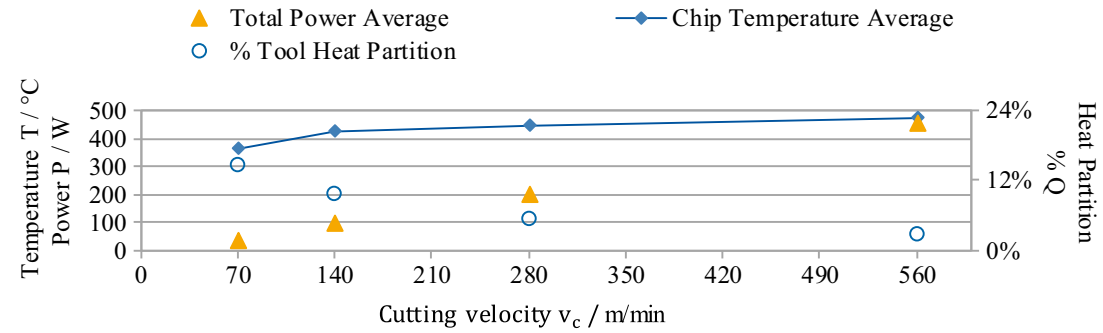




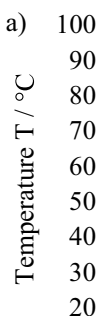
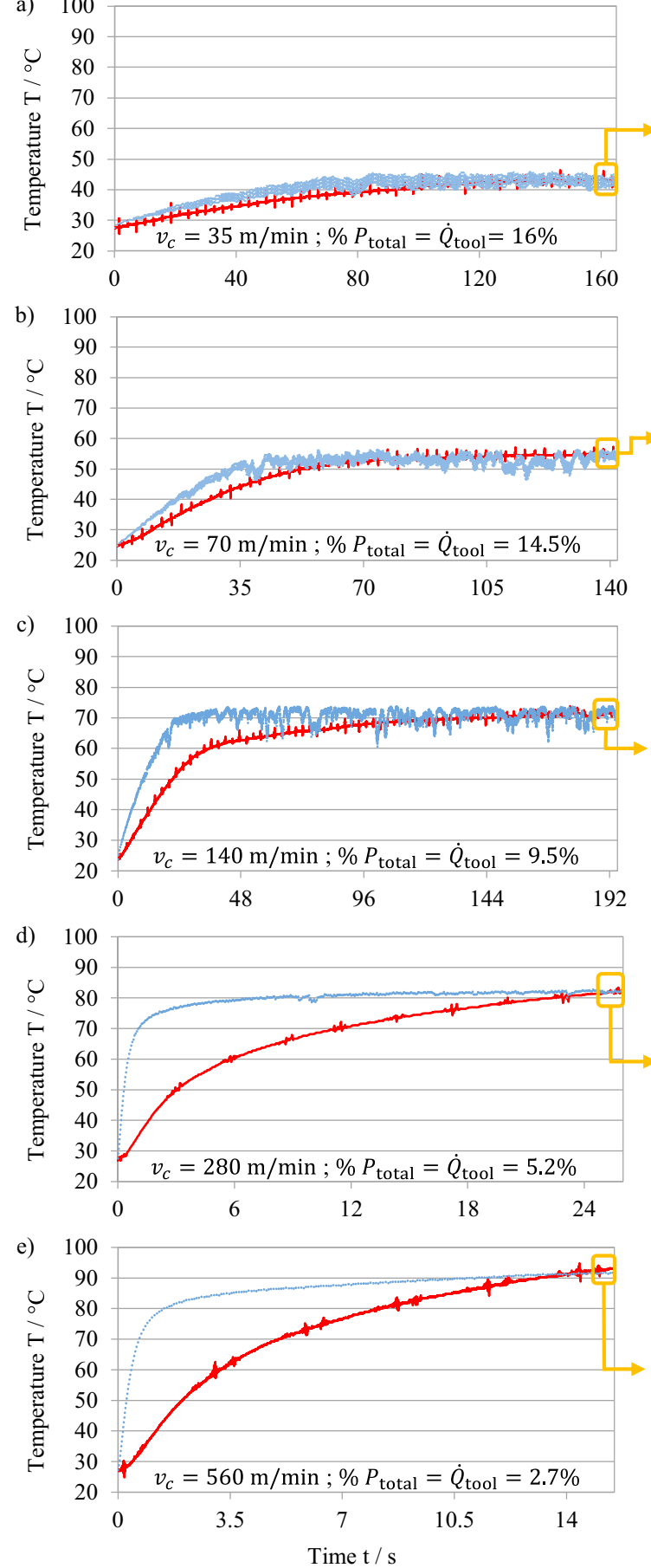

35 $28 \stackrel{-1}{\circ}$ $21 \stackrel{乛}{\rightleftarrows}$

$14 \stackrel{\vec{\rho}}{\dot{s}}$

$7 \stackrel{0}{\gtrless}$
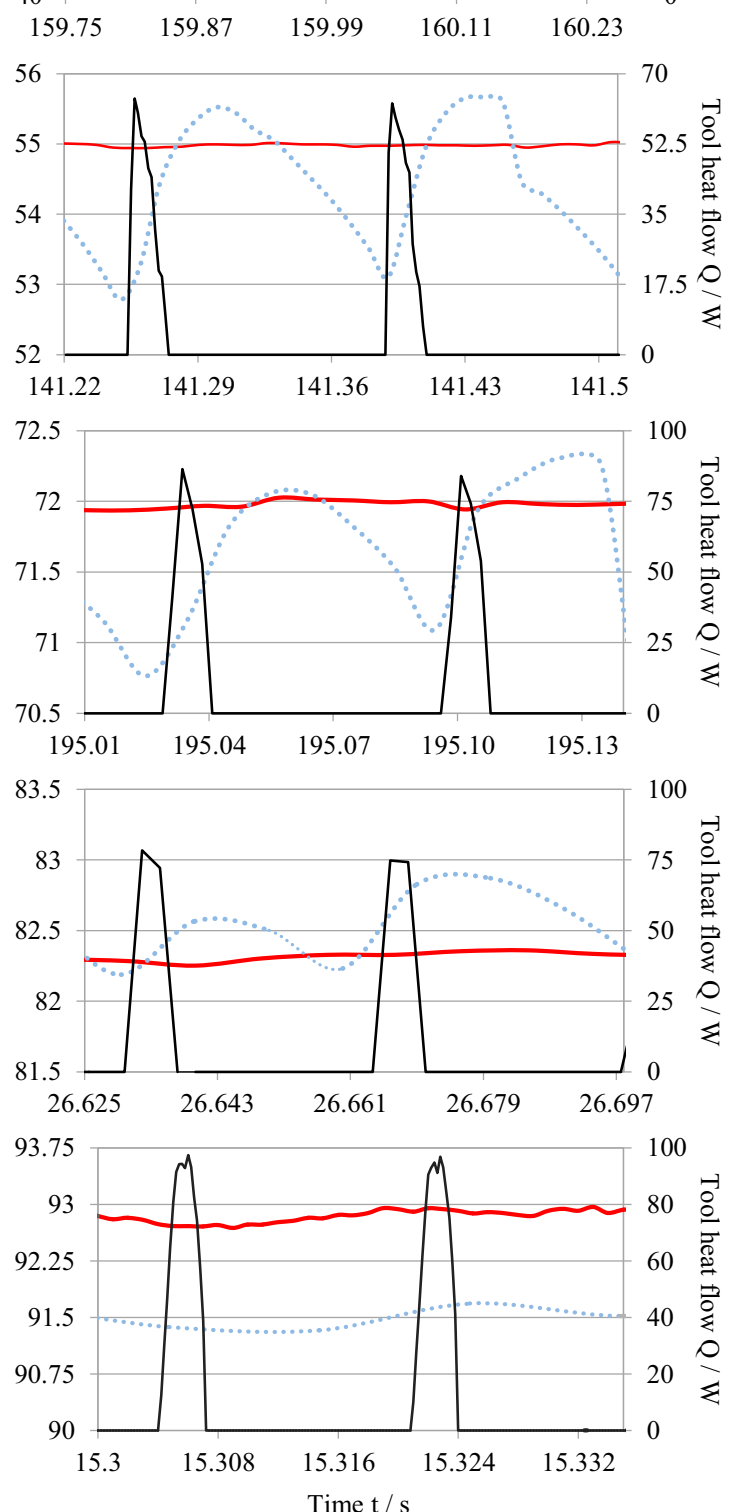

Fig. 6 Measured and simulated temperature trends in the tool depending on cutting velocity: $\mathbf{a} \mathrm{vc}=35 \mathrm{~m} / \mathrm{min}, \mathbf{b} \mathrm{vc}=70 \mathrm{~m} / \mathrm{min}, \mathbf{c} \mathrm{vc}=140 \mathrm{~m} / \mathrm{min}, \mathbf{d}$ $\mathrm{vc}=280 \mathrm{~m} / \mathrm{min}$, and $\mathbf{e} \mathrm{vc}=560 \mathrm{~m} / \mathrm{min}$

The rising average measured chip temperature with cutting velocity indicates such an increasing heat flow and at the same time partition into the chips. Not only more chips are transported away by time with increasing cutting velocity but also chips with a higher temperature and therefore a higher internal energy. However, at relatively low cutting velocities, the relative temperature increase of the chips is highest.
This effect was also observed in [20] and can be explained by the relation between the materials thermal diffusivity and the cutting velocity. With rising cutting velocity, the temperature diffusion from the shear zone into the workpiece is inhibited by the material flow and increasingly directed into the chip. This leads to an increasing heat partition into the chip with cutting velocity and also explains the functionality of high speed cutting 
lowering the heat partition into the workpiece. The results show how heat partitioning can be controlled in terms of process parameter adjusted, in this case the cutting velocity. In this way, the process may be adjusted in relation to specific requirements of surface integrity, thermal-induced distortion, or tool wear.

\section{Summary and conclusions}

A systematic thermodynamic analysis of the dry milling process was conducted by uniting different types of sensor signals for force and temperature into one thermodynamic energy balance. Therefore, a data acquisition system extended by an analytical temperature model for transient volumetric temperature field in the continuous medium was used in order to inversely determine the heat partition of the measured time-variant cutting power conducted into the tool. This heat partition decreased with rising cutting velocity, which can be explained by a changing relation between advective and conductive heat transport. With increasing cutting velocity, the thermal cycle amplitudes decline at the measured and simulated position in the tool. However, the mean temperature rises due to an increasing heat flow into the tool. It stayed below $100{ }^{\circ} \mathrm{C}$ for all investigated cutting velocities.

In order to account for the relatively high reaction time of the thermocouple used, its behavior was included into the analytical temperature model in order to compare measurement and simulation. In this way, also the high frequent temperature cycles at the tool's rake face may be indirectly measured by forward modeling with the inversely determined heat partitions.

The approach may have also the potential for a tool wear monitoring system based on temperature measurements and the resolution of the tool wear affected temperature field in the tool by a forward simulation. However, another important application of the introduced methodology is the quantification of the efficient cooling effect of cooling lubricant on the tool.

Funding information Open Access funding provided by Projekt DEAL. The authors wish to thank the German Research Foundation (DFG) for funding the transregional Collaborative Research Center SFB/TR 96 "Thermo-Energetische Gestaltung von Werkzeugmaschinen" (Aachen, Chemnitz, Dresden), subproject A02.

Open Access This article is licensed under a Creative Commons Attribution 4.0 International License, which permits use, sharing, adaptation, distribution and reproduction in any medium or format, as long as you give appropriate credit to the original author(s) and the source, provide a link to the Creative Commons licence, and indicate if changes were made. The images or other third party material in this article are included in the article's Creative Commons licence, unless indicated otherwise in a credit line to the material. If material is not included in the article's Creative Commons licence and your intended use is not permitted by statutory regulation or exceeds the permitted use, you will need to obtain permission directly from the copyright holder. To view a copy of this licence, visit http://creativecommons.org/licenses/by/4.0/.

\section{References}

1. Klocke F (2011) Manufacturing processes 1 cutting. Springer Verlag, Berlin Heidelberg

2. Yellowley I, Barrow G (1976) The influence of thermal cycling on tool life in peripheral milling. International Journal of Machine Tool Design and Research 16(1):1-12

3. Okushima K, Hoshi T (1962) Thermal crack in the carbide facemilling cutter, 1st report, results obtained from the fundamental cutting experiments. Bulletin of JSME 17:151-160

4. Brinksmeier E, Gläbe R, Klocke F, Lucca DA (2011) Process signatures - an alternative approach to predicting functional workpiece properties. Procedia Engineering 16:44-52

5. Buchkremer S (2017) Irreversible thermodynamics of nano-structural surface modifications in metal cutting. Ph.D. Dissertation, Apprimus, Aachen

6. Biermann D, Kirschner M, Pantke K, Tillmann W, Herper J (2013) New coating systems for temperature monitoring in turning processes. Surf Coat Technol 215:376-380

7. Davies MA, Ueda T, M'Saoubi R, Mullany B, Cooke AL (2007) On the measurement of temperature in material removal processes. CIRP Annals - Manufacturing Technology, 2:581-604

8. Stephenson DA, Ali A (1992) Tool temperatures in interrupted metal cutting. J Eng Ind 113(2):127-136

9. Loewen EG, Shaw MC (1954) On the analysis of cutting tool temperatures. Transactions of the ASME 71:217-231

10. Stephenson DA (1993) Tool-work thermocouple temperature measurements - theory and implementation issues. J Eng Ind 4:432

11. Sato M, Tamura N, Tanaka H (2011) Temperature variation in the cutting tool in end milling. J Manuf Sci Eng 11:21005-1-21005-7

12. Beck JV, Blackwell B, Saint Clair CR (1985) Inverse heat conduction. Wiley, Ill-posed problems, New York

13. Jiang F, Liu Z, Wan Y, Shi Z (2013) Analytical modeling and experimental investigation of tool and workpiece temperatures for interrupted cutting 1045 steel by inverse heat conduction method. J Mater Process Technol 6:887-894

14. Karaguzel U, Bakkal M, Budak E (2016) Modeling and measurement of cutting temperatures in milling. Procedia CIRP 46(1):173176

15. Baohai W, Di C, Xiaodong H, Dinghua Z, Kai T (2016) Cutting tool temperature prediction method using analytical model for end milling. Chin J Aeronaut 6:1788-1794

16. Augspurger T, Koch M, Klocke F, Döbbeler B (2019) Investigation of transient temperature fields in the milling cutter under $\mathrm{CO} 2$ cooling by means of an embedded thermocouple. Procedia CIRP 79:33-38

17. Abel D (2007) Mess- und Regelungstechnik. Verlagsgruppe Mainz $\mathrm{GmbH}$, Aachen

18. Boothroyd G (1963) Temperatures in orthogonal metal cutting. P I Mec Eng 177:789-810

19. Deppermann M, Kneer R (2016) Determination of the heat flux to the workpiece during dry turning by inverse methods. Production Engineering 9(4). https://doi.org/10.1007/s11740-015-0635-6

20. Augspurger T, Bergs T, Döbbeler B (2019) Measurement and modelling of heat partitions and temperature fields in the workpiece for cutting Inconel 718, AISI 1045, Ti6Al4V and AlMgSi0.5. J Manuf Sci Eng 141(16):061007. https://doi.org/10.1115/1.4043311

Publisher's note Springer Nature remains neutral with regard to jurisdictional claims in published maps and institutional affiliations. 